\title{
Epidemiological study of the relation between arthritis of the hip and hip fractures
}

Department of Public Health, University of Sydney, Sydney 2006, Australia

R G Cumming

Department of

Community Medicine Westmead Hospital, Westmead 2145, Australia

R J Klineberg

Correspondence to: Dr Robert G Cumming, Department of Public Health A27, University of Sydney, Sydney, NSW 2006, Australia.

Accepted for publication 21 June 1993

\begin{abstract}
Objectives-To clarify the nature of the relation between hip fractures and osteoarthritis.

Methods-The study was a population based case-control study conducted in Sydney, Australia. Four hundred and sixteen men and women aged 65 years and over were recruited (209 cases, 207 controls). The presence of osteoarthritis was based on self reported pain, swelling, or stiffness of joints in the past year.

Results-Among 189 subjects aged 65 to 79 years, but not in older subjects, there was an inverse relation between self reported arthritis in any joint(s) and risk of hip fracture: the age and gender adjusted odds ratio was $0.52(95 \%$ confidence interval 0.27 to 0.98 ). The prevalence of self reported arthritis of the hip was much lower in patients with hip fracture $(4 \%)$ than in controls randomly selected from the community (13\%); the age and gender adjusted odds ratio was $0.33 \quad(95 \%$ confidence interval $0 \cdot 15$ to $0 \cdot 74)$. There was also an inverse association between the number of joints reported to be affected by arthritis and risk of hip fracture. These associations were not explained by differences between cases and controls in body mass index or physical activity.

Conclusions-The findings of this study support the hypothesis that there is a causal association between osteoarthritis and osteoporosis of the hip.
\end{abstract}

(Ann Rheum Dis 1993; 52: 707-710)

The hip plays a part in two of the most serious disorders that affect the lives of elderly people: osteoarthritis (OA) and fractures. The lifetime risk of hip fracture is $15 \%$ in women and $6 \%$ in men, ${ }^{1}$ and more than $10 \%$ of people aged over 55 years have radiological evidence of OA of the hip. ${ }^{2}$ The two disorders cause a great deal of suffering and lead to significant health service costs. Unfortunately, the aetiologies of these disorders are unclear and so rational preventive programmes cannot be formulated. A complicating issue is that factors that reduce the risk of one disorder may increase the risk of the other.

In 1972 Foss and Byers studied 140 patients with hip fractures and found that only three had radiological evidence of OA of the hip. ${ }^{3}$ Several studies have confirmed that $\mathrm{OA}$ is uncommon in patients with hip fractures. ${ }^{4}$ It also seems likely that subjects with OA of the hip are at reduced risk of osteoporosis. ${ }^{6}$ In the only two studies to examine OA and osteoporosis at the hip (rather than at other skeletal sites), a clear negative association between the two disorders was found. ${ }^{78}$ The simplest explanation for the inverse relation between OA of the hip and hip fracture (and osteoporosis) is the difference in body weight between people with hip fractures (who tend to be underweight) ${ }^{9}$ and people with OA (who tend to be overweight). ${ }^{2}$ Another explanation is that physical activity independently increase the risk of $\mathrm{OA}^{2}$ and reduces the risk of hip fracture. ${ }^{10}$ It is also possible that there is a direct causal relation between the pathological processes of OA and osteoporosis.

We included an interview based assessment of the presence of $\mathrm{OA}$ in an epidemiological study of risk factors for hip fracture in elderly Australians. Our main aim was to describe the relation between OA of the hip and hip fracture in a representative group of men and women aged 65-100 years. We were particularly interested in the previously unstudied role of body weight and physical activity in explaining any association between hip fracture and $\mathrm{OA}$ of the hip. A secondary aim was to explore the more general association between osteoporosis and $\mathrm{OA}$.

\section{Methods}

This population based case-control study was conducted in a geographically defined area within the western suburbs of Sydney, Australia, between 6 March 1990 and 5 August 1991. The total population of this area at the 1986 Australian census was 265000 , including 24000 people aged 65 years or more. Our aim was to compare histories of arthritis in patients with hip fractures (cases) and in a random sample of people without hip fractures (controls). Men and women aged 65 years and over were eligible for the study.

\section{SELECTION OF SUBJECTS}

The geographical area for the study was chosen so that most cases would be admitted to Westmead Hospital, a 1000 bed teaching hospital. Subjects with hip fractures presenting to Westmead Hospital were mostly identified through daily contact with the coordinator of the hip fracture management team. Accident and emergency department log books were reviewed weekly to find any cases of hip 
fracture not identified via the hip fracture team. Eleven other hospitals treating patients with hip fractures from the study population were also contacted regularly to ascertain eligible hip fracture admissions.

Controls living in private homes in the community were selected with an area probability sampling method. Ten census collector's districts from the study area were randomly selected by the Australian Bureau of Statistics and all dwellings in each collector's district were visited: a total of 2560 dwellings. (Collector's districts are groups of dwellings defined by the Australian Bureau of Statistics so that one census collector can cover all dwellings at the five yearly Australian census.) Our aim was to interview all people aged 75 years and over living in the selected collector's districts. In addition, in a $10 \%$ random sample of dwellings, we attempted to interview anyone aged 65-74 years. There were 108 dwellings for which no information on the age of residents was collected. We estimated the number of eligible subjects living in these dwellings (nine subjects) and included this number in the denominator in calculating control response rates.

Six nursing homes and three hostels were selected at random from 28 nursing homes and 12 hostels in the study area. Five people aged 75 years or more were selected at random from each chosen nursing home and hostel. The number of controls selected from these sources reflected the proportion of people in the study area who lived in nursing homes and hostels.

PROXY RESPONDENTS

Elderly subjects with cognitive impairment and those with various other health problems cannot respond to questionnaires. A shortened questionnaire was used to interview proxy respondents for these subjects. Cognitive impairment was the main reason for using the proxy questionnaire (83 subjects). Other reasons were poor English language ability (13 subjects), too ill to answer questions (six subjects), severe deafness (six subjects), aphasia or dysarthria (four subjects), and request by subject (two subjects).

MEASUREMENT OF STUDY VARIABLES

An interviewer administered questionnaire was used to measure exposures of interest. Most cases were interviewed within one week of the hip fracture, but the interview was delayed if it was judged that the patient's cognitive function had not returned to its level before fracture.

The presence of arthritis was based on self reporting. Subjects were asked 'during the past year, have you seen a doctor about pain, swelling, or stiffness in any of your joints?' If the subject answered in the affirmative, he/she was asked to name the affected joint(s). Proxy respondents were simply asked whether or not the subject had seen a doctor in the past year because of arthritis; data on specific joints were not collected.
Other variables relevant to the analyses in this paper were body mass index and physical activity. Calculation of body mass index (weight in kilograms/(height in metres) ${ }^{2}$ ) was based on self reported weight and height. Current physical activity was estimated by hours of housework or work in the garden each week and by the frequency each week of going for walks lasting at least 15 minutes. Past physical activity was based on occupational physical activity at the age of 50 years. Subjects were asked to rate the physical activity in their job as low (mostly sitting or driving), moderate (mostly walking slowly or standing), or high (enough to regularly work up a sweat).

\section{STATISTICAL METHODS}

Data analysis involved crude, stratified, and multivariate methods to produce odds ratios for associations between hip fracture and exposure variables. ${ }^{11}$ Odds ratios from a casecontrol study provide an estimate of the risk of disease (for example, hip fracture) in subjects exposed to some risk factor (for example, OA of the hip) relative to the risk of disease in unexposed subjects. An odds ratio less than 1.0 indicates a reduced risk of disease and an odds ratio greater than 1.0 indicates an increased risk of disease. Age and gender are known to be strong predictors of hip fracture and so all results were adjusted for age and gender. Multiple logistic regression was used to assess arthritis-hip fracture relations while simultaneously controlling for several confounding variables.

\section{Results}

Four hundred and sixteen subjects participated in this study: 209 cases and 207 controls. The response rate was $96 \%$ for cases and $83 \%$ for controls. One hundred and fourteen interviews were by proxy ( 84 cases and 30 controls). Seventy five per cent of cases were recruited from Westmead Hospital. Table 1 gives the age and gender distributions and types of accommodation of cases and controls.

Based on data from all study subjects (directly interviewed subjects and those interviewed by proxy), there was some suggestion that self reported arthritis (joint(s) affected

Table 1 Selected characteristics of cases with hip fractures and controls

\begin{tabular}{lcc}
\hline Characteristic & $\begin{array}{l}\text { No (\%) of } \\
\text { cases } \\
(n=209)\end{array}$ & $\begin{array}{l}\text { No (\%) of } \\
\text { controls } \\
(n=207)\end{array}$ \\
\hline Gender & & \\
$\quad$ Male & $35(17)$ & $70(34)$ \\
Female & $174(83)$ & $137(66)$ \\
Age group (years) & & \\
65-74 & $41(20)$ & $35(17)$ \\
$75-79$ & $37(18)$ & $77(37)$ \\
$80-84$ & $57(27)$ & $60(29)$ \\
$85-89$ & $45(22)$ & $25(12)$ \\
$90-100$ & $29(14)$ & $10(5)$ \\
Accommodation & & \\
Community & $130(62)$ & $166(80)$ \\
Hostel & $10(5)$ & $14(7)$ \\
Nursing home & $69(33)$ & $27(13)$ \\
Proxy respondent needed & $84(40)$ & $30(14)$ \\
\hline
\end{tabular}


Table 2 Adjusted odds ratios (ORs) and 95\% confidence intervals (CIs) for the association between self reported arthritis and the risk of hip fracture

\begin{tabular}{|c|c|c|c|c|}
\hline \multirow[t]{2}{*}{ Variable } & \multicolumn{2}{|c|}{ No of subjects in study $y^{\star}$} & \multirow{2}{*}{$\begin{array}{l}\text { OR adjusted for age } \\
\text { and gender } \\
(95 \% \mathrm{CI})\end{array}$} & \multirow{2}{*}{$\begin{array}{l}\text { Multivariate } \\
\text { adjusted OR† } \\
(95 \% \text { CI) }\end{array}$} \\
\hline & Cases & Controls & & \\
\hline \multicolumn{5}{|l|}{ Arthritis (any joint) } \\
\hline No & 118 & 107 & $1 \cdot 00$ (referent) & $1 \cdot 00$ (referent) \\
\hline Yes & 90 & 100 & $0.78(0.52$ to $1 \cdot 18)$ & $0.93(0.53$ to 1.63$)$ \\
\hline \multicolumn{5}{|l|}{ Site of arthritis } \\
\hline No arthritis & 70 & 88 & $1 \cdot 00$ (referent) & $1 \cdot 00($ referent $)$ \\
\hline Hands & 13 & 33 & $0.38(0.18$ to 0.81$)$ & $0.46(0.19$ to 1.12$)$ \\
\hline Hip & 5 & 23 & $0.33(0.15$ to 0.74$)$ & $0.38(0.12$ to 1.19$)$ \\
\hline Knees & 34 & 47 & $0.80(0.43$ to 1.31$)$ & $1.09(0.55$ to 2.15$)$ \\
\hline Spine & 17 & 35 & $0.53(0.27$ to 1.04$)$ & $0.62(0.29$ to 1.36$)$ \\
\hline Shoulders/wrists & 15 & 33 & $0.55(0.28$ to $1 \cdot 10)$ & $0.88(0.40$ to 1.93$)$ \\
\hline \multicolumn{5}{|c|}{ Number of affected joints } \\
\hline & & 88 & $1 \cdot 00($ referent $)$ & $1 \cdot 00$ (referent) \\
\hline 1 & 23 & 39 & $0.76(0.41$ to 1.38$)$ & $1 \cdot 10(0.53$ to 2.29$)$ \\
\hline 2 & 16 & 24 & $0.74(0.36$ to 1.55$)$ & $0.85(0.37$ to 1.92$)$ \\
\hline 3 & 5 & 11 & $0.43(0.13$ to 1.49$)$ & $0.64(0.37$ to 2.67$)$ \\
\hline$\geqslant 4$ & 5 & 15 & $0.33(0.13$ to 0.86$) \ddagger$ & $0.55(0.17$ to 1.71$) \ddagger$ \\
\hline
\end{tabular}

^Age and gender adjusted results for arthritis (any joint) are based on data from directly interviewed subjects and from proxy respondents; other results are based on data from directly interviewed subjects only.

†ORs adjusted for age, gender, body mass index, current physical activity (see under Methods), and occupational physical activity at age 50 years

$\ddagger$ Test for trend: $\mathrm{p}<0.05$.

unspecified) was associated with a reduced risk of hip fracture (age and gender adjusted odds ratio (OR) $0 \cdot 8,95 \%$ confidence interval (CI) $0 \cdot 5$ to $1 \cdot 2)$. This association depended on age (but not on gender). Among those aged 65-79 years (189 subjects), self reported arthritis was associated with a statistically significant $(\mathrm{p}<0.05)$ reduction in the risk of hip fracture (age and gender adjusted OR $0.5,95 \%$ CI 0.3 to $1 \cdot 0)$. Among those aged $80-100$ years, however, there was no statistically significant association between self reported arthritis and hip fracture (adjusted OR $1 \cdot 1,95 \%$ CI 0.6 to $2 \cdot 0$ ).

Table 2 gives the associations between arthritis of particular joints (based on self reported pain, swelling, or stiffness in any joints that caused the subject to see a doctor in the past year) and the risk of hip fracture. These data were not available for subjects interviewed by proxy. All ORs were less than $1 \cdot 0$, with statistically significant $(p<0 \cdot 05)$ ORs for arthritic symptoms of the hand (OR 0.4 ) and hip (OR $0 \cdot 3)$. There was also a statistically significant inverse trend $(p=0.04)$ between the number of joints with symptoms of arthritis and the risk of hip fracture. The inverse associations between hip fracture and self reported arthritis were present at all ages studied and in men and women.

Table 3 Adjusted odds ratios (ORs) and 95\% confidence intervals (CIs) for the association between body mass index and physical activity and the presence of joint symptoms. Control subjects only

\begin{tabular}{|c|c|c|c|c|}
\hline \multirow[t]{2}{*}{ Variable } & \multicolumn{2}{|c|}{ Hip symptoms } & \multicolumn{2}{|c|}{ Knee symptoms } \\
\hline & $\begin{array}{l}\text { Present/ } \\
\text { absent }\end{array}$ & $\begin{array}{l}\text { Adjusted } O R^{\star} \\
(95 \% \text { CI })\end{array}$ & $\begin{array}{l}\text { Present/ } \\
\text { absent }\end{array}$ & $\begin{array}{l}\text { Adjusted } O R^{\star} \\
(95 \% C I)\end{array}$ \\
\hline \multicolumn{5}{|l|}{ Body mass index (tertile) } \\
\hline Low & $6 / 25$ & 1.00 (referent) & $12 / 25$ & $1 \cdot 00$ (referent) \\
\hline Middle & $8 / 35$ & $0.95(0.23$ to 3.93$)$ & $14 / 35$ & $0.93(0.32$ to 2.68$)$ \\
\hline High & $8 / 19$ & $4 \cdot 14(0 \cdot 84$ to $20 \cdot 42)$ & $17 / 19$ & $2 \cdot 65(0 \cdot 86$ to $8 \cdot 17)$ \\
\hline \multicolumn{5}{|c|}{ Occupational physical activity at age 50 years } \\
\hline No paid employment & & $0.64(0.11$ to 3.74$)$ & $18 / 30$ & $2.52(0.82$ to 7.69$)$ \\
\hline Low activity & $5 / 26$ & 1.00 (referent) & $7 / 26$ & 1.00 (referent) \\
\hline Moderate activity & $8 / 27$ & $2.05(0.59$ to 7.02$)$ & $14 / 27$ & $1.72(0 \cdot 70$ to 4.21$)$ \\
\hline High activity & $4 / 5$ & $5 \cdot 68(0 \cdot 70$ to $46 \cdot 0)$ & $7 / 5$ & $4.39(1.23$ to 15.7$)$ \\
\hline
\end{tabular}

${ }^{\star}$ ORs are adjusted for age and gender. Results are based on data from directly interviewed contro subjects only.
Logistic regression models were used to assess whether confounding by physical activity and body mass index could explain the observed protective effect of self reported arthritis at various joints on hip fracture risk (table 2). Although the size of effects was reduced, the protective effect of arthritis was still evident. For example, the adjusted OR for arthritis of the hip and hip fracture was 0.4 $(95 \%$ CI $0 \cdot 2$ to $1 \cdot 1)$. The trend for a lower risk of hip fracture with increasing number of joints with symptoms of arthritis also persisted after adjusting for body mass index and physical activity. These findings suggest that the protective effect of self reported arthritis was independent of body weight and physical activity.

The control subjects in this study were a random sample of the population, enabling some assessment of the role of body weight and physical activity in the aetiology of OA in the elderly. As shown in table 3, increased weight was associated with an increased risk of arthritic symptoms at the hip and knee among control subjects in this study, as was a high level of occupational physical activity at age 50 years.

\section{Discussion}

This study confirms that there is a strong inverse relation between OA of the hip and hip fracture. Compared with people without symptoms of arthritis of the hip, people with symptoms had one third the risk of hip fracture. We also found some evidence that people with a general propensity to OA (as judged by the number of affected joints) were at reduced risk of osteoporosis (as judged by the presence of hip fracture). These associations were independent of weight and physical activity.

The main weakness of this study was the way in which OA was defined. There was no radiological assessment of joints; instead, we relied on self reports of joint symptoms in the past year (pain, swelling, or stiffness severe enough to see a doctor) for the diagnosis of OA. Several studies have shown that there is an imperfect relation between radiological evidence of $\mathrm{OA}$ and joint symptoms. For example, Lawrence $e t$ al found that only $61 \%$ of subjects aged 55 years or more with definite radiological evidence of $\mathrm{OA}$ of the hip (joint narrowing, sclerosis, or cysts) reported hip pain. ${ }^{12}$ In this same study, $11 \%$ of subjects without radiological OA had hip pain. Croft et al found that only $48 \%$ of those with definite radiographic evidence of OA of the hip had hip pain. ${ }^{13}$ Obviously, using joint pain and other symptoms to diagnose $\mathrm{OA}$ will result in the misclassification of subjects-many subjects with $\mathrm{OA}$ will be missed and some subjects without OA will be incorrectly diagnosed as having this disorder (including people with arthritic disorders other than $\mathrm{OA}$ ). The net effect of misclassification rates that are the same in cases and controls (as seems likely in our study) is to make it more difficult to find real associations. ${ }^{14}$ Hence our findings on the 
relation between OA of the hip and hip fracture probably underestimate the magnitude of the true relation.

Reliance on self reported joint symptoms for the classification of $\mathrm{OA}$ could explain our failure to find any relation between OA and hip fractures in subjects aged 80 years and over. It is possible that joint symptoms are a less accurate marker of $\mathrm{OA}$ in the very elderly; for example, people in this age group tend to be less active and so may be less likely to experience symptoms. Poor measurement makes it difficult to identify associations. ${ }^{14}$

To exclude minor joint problems unlikely to have been due to significant $O A$, we used a definition of $\mathrm{OA}$ that required joint symptoms to be severe enough to seek medical advice. It is, however, conceivable that this could have introduced some bias into our study. For example, subjects who consult doctors about OA may be provided with home aids that reduce the risk of falling and, hence, reduce the risk of hip fractures.

Previous studies of OA of the hip and hip fracture and osteoporosis have been criticised because of the way in which subjects were selected. ${ }^{6}$ In the present study we collected some information on arthritis from nearly all (94\%) patients with hip fractures in a geographically defined population and compared these with similar data from a random sample of subjects living in the same population. Thus selection bias is unlikely to explain the results of our study.

The validity of our findings for hip fracture and OA is supported by the results of our analyses of the relation between body mass index and physical activity and arthritic symptoms at the hip and knee (table 3 ). We found that increased weight and a physically demanding occupation at an age of 50 years increased the risk of symptoms of arthritis at the hip and knee. The fact that these findings, particularly for the knee, are consistent with studies using a radiological diagnosis of $\mathrm{OA}^{2}$ suggests that our results for the relation of OA of the hip with hip fracture are likely to be valid.

Why is there an inverse relation between $\mathrm{OA}$ of the hip and the risk of hip fracture? We did not find any evidence that the relation is due to confounding by body weight or physical activity, or both. Hip fractures result from a combination of low bone density ${ }^{15}$ and falls. Osteoarthritis may be associated with an increased risk of falling, ${ }^{16}{ }^{17}$ suggesting that any causal relation between $\mathrm{OA}$ and a reduced risk of hip fracture must be mediated via bone density (osteoporosis).

It has been proposed that increased bone density reduces the mechanical ability of subchondral bone to deform under impact loads. ${ }^{18}$ This could lead to damaged articular cartilage and OA. An epidemiological study supports this theory. ${ }^{19}$ Women initially free of
OA of the hands were studied over a 23 year period. Those women with higher metacarpal cortical area (a measure of bone density) at baseline were more likely to develop OA of the hands during follow up. This suggests that osteoporosis protects against $\mathrm{OA}$, and not vice versa.

If high bone density increases the risk of developing OA, then it is possible that an adverse effect of treatment for osteoporosis could be the development of OA. Furthermore, the best way of testing the hypothesis that osteoporosis leads to OA might be to include an assessment of $\mathrm{OA}$ as an outcome in randomised trials of treatment for low bone density.

In summary, we found that subjects with symptoms of arthritis of the hip had a markedly reduced risk of hip fracture. This suggests that OA of the hip should be included in the list of factors that protect against hip fracture. The association between hip fracture and OA was independent of body weight and physical activity, supporting the hypothesis that there is a direct causal relation between osteoporosis and $\mathrm{OA}$.

1 Cummings S R, Black D M, Rubin S M. Lifetime risk of hip, Colles', or vertebral fracture and coronary heart disease among white postmenopausal women. Arch Intern Med 1989; 149: 2445-8.

2 Felson D T. Epidemiology of hip and knee osteoarthritis Epidemiol Rev 1988; 10: 1-28.

3 Foss M V L, Byers P D. Bone density, osteoarthritis of the hip, and fracture of the upper end of the femur. Ann Rheum Dis 1972; 31: 259-64.

4 Solomon L, Schnitzler C M, Browett J P. Osteoarthritis of the hip: the patient behind the disease. Ann Rheum Dis 1982; 41: 118-25.

5 Weintraub S, Papo J, Ashkenazi $M$, Tardiman R, Weissman $\mathrm{S}$ L, Salama R. Osteoarthritis of the hip and fractures of S L, Salama R. Osteoarthritis of the hip and fractures of
the proximal end of the femur. Acta Orthop Scand 1982; 53: $261-4$.

6 Hordon L D, Wright V, Smith M A. Bone mass in osteoarthritis. Ann Rheum Dis 1992; 51: 823-5.

7 Cooper C, Cook P L, Osmond C, Fisher L, Cawley M I. Osteoarthritis of the hip and osteoporosis of the proxima femur. Ann Rheum Dis 1991; 50: 540-2.

8 Knight S M, Ring E F, Bhalla A K. Bone mineral density and osteoarthritis. Ann Rheum Dis 1992; 51: 1025-6.

9 Cummings S R, Kelsey J L, Nevitt M C, O'Dowd K J. Epidemiology of osteoporosis and osteoporotic fractures. Epidemiol Rev 1985; 7: 178-208.

10 Paganini-Hill A, Chao A, Ross R K, Henderson B E Exercise and other factors in the prevention of hip fracture: the Leisure World Study. Epidemiology 1991; 2: $16-25$.

11 Rothman K J. Modern epidemiology. Boston: Little, Brown, 1986.

12 Lawrence J S, Bremner J M, Bier F. Osteoarthrosis. Ann Rheum Dis 1966; 25: 1-24.

13 Croft P, Cooper C, Wickham C, Coggon D. Defining osteoarthritis of the hip for epidemiologic studies. $A m \mathcal{F}$ Epidemiol 1990; 132: 514-22.

14 Copeland K T, Checkoway H, McMichael A J, Holbrook R H. Bias due to misclassification in the estimation of relative risk. Am f Epidemiol 1977; 105: 488-95.

15 Cummings S R, Black D M, Nevitt M C, et al. Bone density at various sites for prediction of hip fracture. Lancet 1993; 341: $72-5$.

16 Nevitt M C, Cummings S R, Kidd S, Black D. Risk factors for recurrent non-syncopal falls. $\mathcal{F} A M A$ 1989; 261: 2663-8.

17 Campbell A J, Borrie M J, Spears G F. Risk factors for falls in a community-based prospective study of people 70 years and older. $\mathcal{F}$ Gerontol $1989 ; 44: \mathrm{M} 112-7$.

18 Radin E L. Mechanical aspects of osteoarthritis. Bull Rheum Dis 1976; 26: 862-5.

19 Sowers M, Zobel D, Weissfeld L, Hawthorne V M, Carman W. Progression of osteoarthritis of the hand and metacarpal bone loss. A twenty-year followup of incident cases. Arthritis Rheum 1991; 34: 36-42. 